Check for updates

Cite this: RSC Adv., 2018, 8, 9723

Received 12th February 2018

Accepted 1st March 2018

DOI: 10.1039/c8ra01365a

rsc.li/rsc-advances

\title{
Sodium periodate/TEMPO as a selective and efficient system for amine oxidation $\dagger$
}

\author{
P. Galletti, (D)* G. Martelli, G. Prandini, C. Colucci and D. Giacomini (D)*
}

A new metal-free protocol for promoting oxidation of amines in aqueous-organic medium was developed. $\mathrm{NaIO}_{4}$ and TEMPO as the catalyst emerged as the most efficient and selective system for oxidation of differently substituted benzyl amines to the corresponding benzaldehydes without overoxidation. Unsymmetrical secondary amines underwent selective oxidation only at the benzylic position thus realising an oxidative deprotection of a benzylic group with an easy amine recovery.

\section{Introduction}

Oxidation chemistry plays a central role in organic synthesis and many industrial processes rely on oxidations as key steps. Oxidation reactions are indeed an important tool for the interconversion of functional groups and are largely exploited for alkane or alcohol transformations. ${ }^{1}$ Oxidation of amines has been less explored but it can afford a large panel of products (Fig. 1), some oxidations aim at the nitrogen atom, other at both nitrogen and carbon atoms. Thus, selective reagents and controlled conditions are required to get a specific functional group. Moreover, pressure from society and regulation is placing important restrictions on industrial oxidation technology, with emphasis on the need for sustainable and environmentally friendly processes.

The oxidation of amines to get aldehydes is a particularly interesting transformation and despite its efficiency, the most common protocols suffer from the required use of stoichiometric amounts of toxic metal-containing reagents, such as $\mathrm{KMnO}_{4},{ }^{2}$ argentic picolinate, ${ }^{3} \mathrm{ZnCr}_{2} \mathrm{O}_{7},{ }^{4}$ and nicotinium dichromate, ${ }^{5}$ or palladium- ${ }^{6}$ copper- $^{7}{ }^{7}$ and ruthenium-based ${ }^{8}$ catalysts. In addition, these methodologies are sometimes affected by over oxidation of aldehydes to carboxylic acids.

The synthesis of imines via oxidative coupling of primary amines or oxidation of secondary amines were recently explored using metals or metal-complexes as catalysts. ${ }^{9}$ Recently, photocatalysts such as titanium or niobium salts by UV irradiation, and mesoporous- $\mathrm{C}_{3} \mathrm{~N}_{4},{ }^{10} \mathrm{CdS},{ }^{11} \mathrm{Au}-\mathrm{Pd} / \mathrm{ZrO}_{2},{ }^{12}$ conjugated microporous poly(benzooxadiazole) networks ${ }^{13}$ and hollow microporous organic networks ${ }^{14}$ by visible irradiation have been reported as active and highly selective catalysts for this oxidation. However, pure oxygen at high pressure is required. In

Department of Chemistry "G. Ciamician" University of Bologna, Bologna 40126, Italy. E-mail: paola.galletti@unibo.it; daria.giacomini@unibo.it

$\dagger$ Electronic supplementary information (ESI) available: General procedures for the synthesis of the secondary amines 7-11 via imines $\mathbf{4 a}, \mathbf{4 m}, \mathbf{4 n}, \mathbf{4 o}$, and $\mathbf{4 t}$, and NMR spectra of compounds. See DOI: 10.1039/c8ra01365a recent contributions $\mathrm{Au} / \mathrm{TiO}_{2}{ }^{15} \mathrm{BiVO}_{4}$ with a copper complex, ${ }^{16}$ and goldthiolates/ $\mathrm{TiO}_{2}$ nanoclusters using atmospheric oxygen under visible light were used for benzylamine oxidation to secondary imines. ${ }^{17}$

Many of these oxidation systems still require harsh reaction conditions and produce metal-containing wastes. ${ }^{18}$ Therefore, as an improvement, some metal-free methodologies were studied. Recently synthetic quinone-based catalysts for the efficient aerobic oxidation of amines to imines were reviewed. ${ }^{19}$ These methods have been inspired by copper amine oxidases, a family of metallo-enzymes which selectively converts primary amines into aldehydes, using molecular oxygen through the cooperation of a quinone-based cofactor. As an example of oxidation with enzymes from our research group, ${ }^{20}$ we reported a selective bio-oxidation of amines to aldehydes or imines using

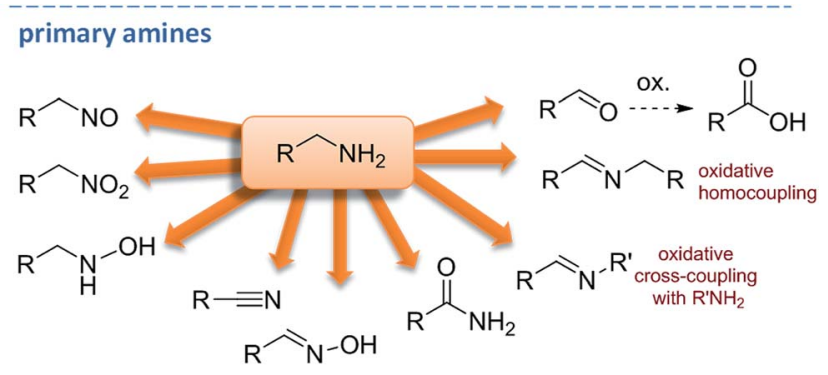

secondary amines

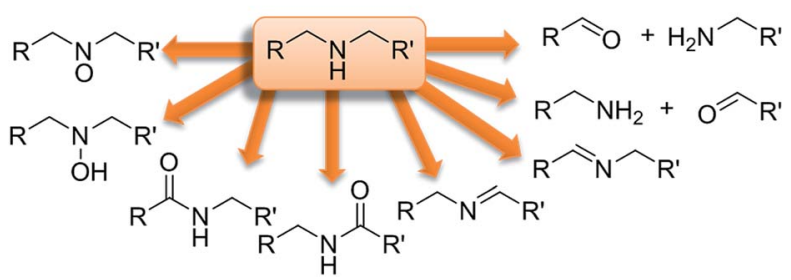

Fig. 1 Functional group diversity generated by oxidation of primary or secondary amines. 
laccase by Trametes $v s$. and TEMPO as mediator. ${ }^{21}$ Stable nitroxyl radical TEMPO (2,2,6,6-tetramethylpiperidine-1-oxyl) plays a salient role as catalyst in metal-, organo- or biocatalysed oxidation processes and significant progress in terms of catalytic efficiency and substrate applicability has been achieved, ${ }^{22}$ including oxidation of amines. ${ }^{23}$ Concerning the bio-oxidation of amines, Contente et al. reported an application of a flow-based biocatalysis in the oxidation of amines to aldehydes by an immobilized transaminase with sodium pyruvate as co-oxidant, ${ }^{24}$ and Zheng et al. reported the $\alpha$-oxydation of cyclic amines to amides by whole-cell biotransformation. ${ }^{25}$

Using metal-free oxidants, Gaspa et al. reported a mild and solvent-free oxidation of primary amines to aldehydes, ketones, and nitriles by $N$-chlorosuccinimide under ballmilling conditions. ${ }^{26}$ Very recently Brisar et al. described the use of pyrazine cation for the aerobic oxidation of amines to imines. ${ }^{27}$ Concerning the use of inorganic metal-free oxidants, choline peroxydisulfate was successfully applied to a selective oxidation of secondary amines to hydroxylamines. ${ }^{28}$ De Souza et al. reported a selective synthesis of imines and amides by oxidative coupling of amines using $\mathrm{NaOCl} .^{29}$ Hypochlorite indeed is a widely used and cheap oxidant but its solutions liberate toxic gases such as chlorine when acidified or heated. Moreover, when chlorinebased oxidants are used in conjunction with organic compounds the formation of potentially harmful organochlorine compounds is often an inevitable side reaction (chloramines, dioxines, etc), thus favoring the development and use of chlorine-free oxidant systems. ${ }^{30}$

From this point of view, $\mathrm{NaIO}_{4}$ can be considered a promising oxidative agent, since it is a relatively cheap reagent, exploitable in water or aqueous solvents. ${ }^{31}$ Moreover, it is active at neutral $\mathrm{pH}$ and under mild conditions which is compatible with a wide range of functionalities and for this reason it has been extensively used in oxidation reactions for organic synthetic applications. Sodium periodate has also been often used in combination with other more expensive oxidants, in this case the use of periodates in stoichiometric amounts as primary oxidants allows the use of these expensive oxidants in catalytic amounts. ${ }^{31}$

As an ongoing interest in sustainable oxidation methodologies, we now report on the use of the stable radical TEMPO as catalyst in combination with metal-free oxidation systems in aqueous medium to oxidize amines. We focused on the promising system $\mathrm{NaIO}_{4} /$ TEMPO to selectively transform amines into the corresponding aldehydes and exploiting the reaction selectivity towards benzylic amines to develop a new protocol for removal of pMeO-benzylic group on secondary amines. Application of the oxidation system to cyclic amines in turn gave preferentially the unsaturated derivatives.

\section{Results and discussion}

Starting from our previous results with laccase Tv in the presence of TEMPO as catalyst, we initially investigated some inorganic oxidants for a selective oxidation of amines. ${ }^{21}$ To increase the sustainability of the process, we chose as reaction solvent an homogeneous aqueous-organic mixture able to dissolve both the starting amine and the oxidant, and mixtures of water and acetonitrile turned out to be suitable. We started our investigation using pOMe-benzylamine $\mathbf{1 a}$ as model substrate in $\mathrm{H}_{2} \mathrm{O}$ / $\mathrm{CH}_{3} \mathrm{CN}(\mathrm{v} / \mathrm{v}=2: 1)$ (Table 1) and some inorganic oxidants were screened such as $\mathrm{NaClO}, \mathrm{NaClO}_{2} / \mathrm{NaClO}$ (cat), $\mathrm{NaClO} / \mathrm{NaBr}$ (cat) following the Anelli-Montanari's protocol, ${ }^{32} \mathrm{Na}_{2} \mathrm{~S}_{2} \mathrm{O}_{8}$, and $\mathrm{NaIO}_{4}$. Data in Table 1 illustrate the effect of some parameters on the reaction efficiency and on the distribution of the oxidation products.

Table 1 Screening of TEMPO catalyzed oxidation systems for pOMe-benzylamine $1 a^{a}$

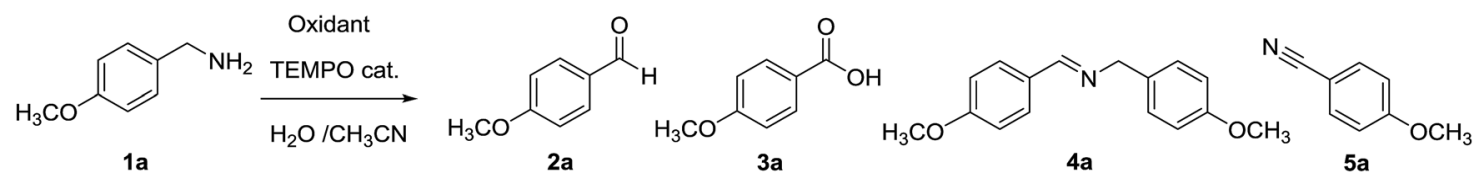

\begin{tabular}{|c|c|c|c|c|c|c|}
\hline Entry & Oxidant & TEMPO (mol\%) & Additive & Time (h) & Conv. (\%) & Product $^{b}(Y \%)$ \\
\hline 1 & $\mathrm{NaClO}_{2}(2$ eq. $) / \mathrm{NaClO}$ (0.05 eq.) & 10 & & 96 & 15 & 4a (12) \\
\hline 2 & $\mathrm{NaClO}_{2}(2$ eq.) $/ \mathrm{NaClO}$ (0.05 eq.) & 10 & AcOH, 1 eq. & 144 & 98 & $\mathbf{2 a}(10), 3 \mathbf{a}(40), 5 \mathbf{a}(50)$ \\
\hline 4 & $\mathrm{NaClO}$ (1 eq. $) / \mathrm{NaBr}$ (0.15 eq.) & 2 & $\mathrm{AcOH}, 1$ eq. & 72 & 44 & $2 \mathbf{a}(27)$ \\
\hline 5 & $\mathrm{NaClO}$ (1 eq.) $/ \mathrm{NaBr}$ (0.15 eq.) & 10 & AcOH, 1 eq. & 72 & 80 & $2 \mathbf{a}(73)$ \\
\hline 6 & $\mathrm{NaClO}(1 \mathrm{eq}.) / \mathrm{NaBr}(0.15 \text { eq. })^{c}$ & 20 & $\mathrm{AcOH}, 1 \mathrm{eq}$. & 72 & 84 & $2 \mathbf{a}(77)$ \\
\hline 9 & $\mathrm{NaIO}_{4}$ (1 eq.) & - & & 24 & 63 & $2 \mathbf{a}(42), 4 a(16)$ \\
\hline 10 & $\mathrm{NaIO}_{4}$ (1 eq.) & 2 & & 72 & 75 & 2a (45), 4a (49) \\
\hline 11 & $\mathrm{NaIO}_{4}(1$ eq.) & 10 & & 24 & 86 & $2 \mathbf{a}(73)$ \\
\hline 12 & $\mathrm{NaIO}_{4}$ (1 eq.) & - & $\mathrm{AcOH}, 1$ eq. & 20 & 13 & $2 a(12)$ \\
\hline 13 & $\mathrm{NaIO}_{4}(1 \mathrm{eq})$. & 10 & $\mathrm{AcOH}, 1$ eq. & 20 & $>99$ & $2 \mathbf{a}(92)$ \\
\hline
\end{tabular}

${ }^{a}$ See GP1 in the Experimental section. ${ }^{b}$ Isolated yields by solvent extraction after acid work-up (see Experimental section). ${ }^{c}$ Solvent volume 6 mL. 
Table 2 Optimization of reaction conditions with $\mathrm{NalO}_{4} / \mathrm{TEMPO}$ oxidation system ${ }^{a}$

\begin{tabular}{|c|c|c|c|c|c|}
\hline \multirow[b]{2}{*}{ Entry } & \multirow{2}{*}{$\mathrm{H}_{2} \mathrm{O} / \mathrm{CH}_{3} \mathrm{CN}$, } & \multicolumn{2}{|c|}{ 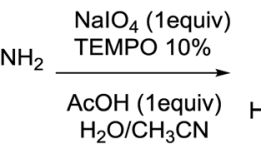 } & $2 a$ & \multirow[b]{2}{*}{$Y^{b}(\%)$} \\
\hline & & Vol. (mL) & Time (h) & Conv. (\%) & \\
\hline 1 & $2 / 1$ & 15 & 20 & $>99$ & 92 \\
\hline 2 & $2 / 1$ & 15 & 6 & 44 & 43 \\
\hline 3 & $2 / 1$ & 10 & 6 & 96 & 86 \\
\hline 4 & $2 / 1$ & 5 & 6 & 95 & $92^{c}$ \\
\hline 5 & $1 / 1$ & 10 & 6 & 86 & 86 \\
\hline 6 & $1 / 2$ & 10 & 6 & 60 & 58 \\
\hline 7 & $\mathrm{CH}_{3} \mathrm{CN}$ & 10 & 6 & 27 & $25^{c}$ \\
\hline 8 & $\mathrm{H}_{2} \mathrm{O}$ & 10 & 6 & 34 & 10 \\
\hline
\end{tabular}

${ }^{a}$ See GP1 in the experimental section. ${ }^{b}$ Isolated yields of $2 a$ as single compound by solvent extraction after acid work-up (see Experimental section). ${ }^{c}$ Heterogeneous solution because of insolubility of periodate.
The aqueous reaction medium brought an initial drawback deriving from a basic $\mathrm{pH}$ resulting on dissolution of amine 1a in the aqueous-organic solvent mixture (observed $\mathrm{pH}=12$ ). This basicity deactivated in some cases the oxidation system, thus giving low conversions and yields (entries 1, 7, and 9, Table 1). To overcome this problem, the addition of one equivalent of acetic acid was successful in decreasing the initial $\mathrm{pH}$ to 7 and afforded a substantial improvement on both conversions and yields (entries 2, 3, 5, and 8, Table 1). The radical TEMPO showed to be an effective organocatalyst in promoting the reaction with almost all the oxidants with an optimized amount of $10 \mathrm{~mol} \%$ to increase both yields and selectivity (Table 1 , for NaClO-NaBr see entries $4-6$, for $\mathrm{Na}_{2} \mathrm{~S}_{2} \mathrm{O}_{8}$ see entries $7-8$, for $\mathrm{NaIO}_{4}$ see entries 12 and 13). Concerning the effect of the oxidation system on products selectivity, $\mathrm{NaClO}_{2} / \mathrm{NaClO}$ or $\mathrm{NaClO}$ alone are efficient but poorly selective, affording almost complete conversions but a mixture of products: aldehyde/acid/ nitrile with $\mathrm{NaClO}_{2} / \mathrm{NaClO}$, and an aldehyde/nitrile $1: 3$ mixture with $\mathrm{NaClO}$ (Table 1, entries 2 and 3). $\mathrm{NaClO}-\mathrm{NaBr}$ and $\mathrm{Na}_{2} \mathrm{~S}_{2} \mathrm{O}_{8}$ are very selective oxidants with an exclusive formation of the

Table 3 Scope of primary amine oxidation with $\mathrm{NaIO}_{4} / \mathrm{TEMPO}^{a}$

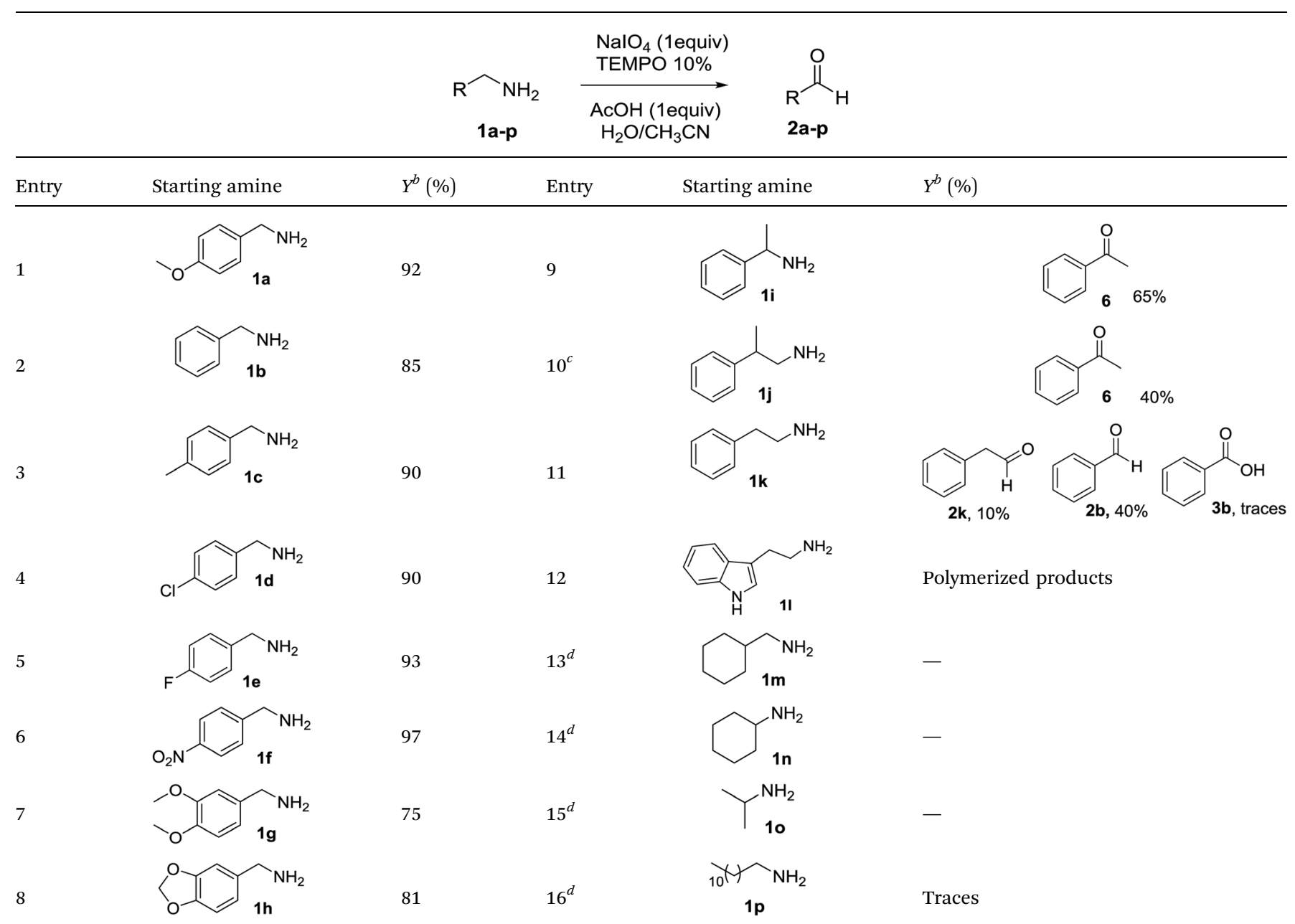

${ }^{a}$ Reaction conditions: see GP2 in the Experimental section. ${ }^{b}$ Isolated yields by solvent extraction after acid work-up. ${ }^{c}$ Solvent volume 10 mL. ${ }^{d}$ An equivalent of trifluoroacetic acid (TFA) was added in the basic organic extract (see Experimental section). 


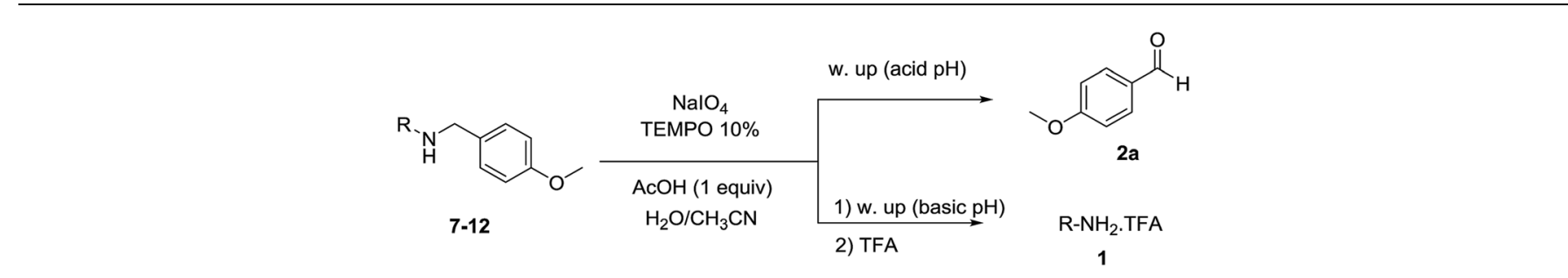

Entry Starting amine

\footnotetext{
${ }^{a}$ Reaction conditions: see GP3 in the Experimental section. ${ }^{b}$ Isolated as single compound by solvent extraction after acid work-up (see Experimental section). ${ }^{c}$ Amines were isolated as ammonium salts in the basic organic extract by adding an equivalent of trifluoroacetic acid (TFA). ${ }^{d} 20 \%$ of TFA salt of $1 \mathrm{a}$ was obtained.
}

aldehyde 2a but do not reach complete conversions. $\mathrm{NaIO}_{4}$ alone or with TEMPO $2 \mathrm{~mol} \%$ gave mixtures of aldehyde and imine (Table 1 entries 9 and 10), but on increasing the amount of TEMPO to $10 \%$ it yielded the aldehyde only. Finally, $\mathrm{NaIO}_{4}$ in the presence of 1 equiv. of acetic acid and 10\% TEMPO gave complete conversion with an excellent isolated yield of $2 \mathrm{a}$ (Table 1, entry 13). Thus, from the initial screening, the system $\mathrm{NaIO}_{4} / \mathrm{TEMPO} /$ AcOH emerged as the most efficient and selective method to oxidize the model amine 1a to the aldehyde 2a. ${ }^{1} \mathrm{H}$ NMR spectra representing products distribution in crude mixtures of selected entries of Table 1 are reported in Fig. $1 \mathrm{~S}$ in ESI.†

We next examined the influence of solvent mixtures and the amount of TEMPO with $\mathrm{NaIO}_{4}$ on conversions and yields (Table 2). The mixture $\mathrm{H}_{2} \mathrm{O} / \mathrm{CH}_{3} \mathrm{CN} 2: 1$ gave the best result, but on shortening the reaction time, the efficiency decreased (Table 1 , entries 1 and 2).

On increasing the concentration of $1 \mathrm{a}$ by diminishing the total solvent volume, the system recovered efficiency with good conversions and isolated yields in a shorter reaction time (Table 2 , entries 3 and 4). An increase of the relative amount of $\mathrm{CH}_{3} \mathrm{CN}$ in $\mathrm{H}_{2} \mathrm{O}$ was not efficient (Table 2, entries 5 and 6) and worse results were obtained either in pure $\mathrm{CH}_{3} \mathrm{CN}$ because of the insolubility of $\mathrm{NaIO}_{4}$, or in $\mathrm{H}_{2} \mathrm{O}$ alone because of the insolubility of the starting amine 1a (Table 2 entries 7 and 8).
With the optimized conditions in hand, the oxidation protocol with $\mathrm{NaIO}_{4} / \mathrm{TEMPO} / \mathrm{AcOH}$ was then applied to a series of commercial aldehydes to test the substrate scope (Table 3). Benzylamines 1a-f with different substituents on the aromatic ring were selectively and efficiently oxidized to the corresponding benzaldehydes 2a-f; both electron donating and electronwithdrawing substituents on the phenyl ring are well tolerated, giving access to the corresponding aldehydes in good to excellent isolated yields. 1-Phenyl ethylamine 1i gave acetophenone $\mathbf{6}$ as expected, whereas its structural isomer 2-phenylethylamine $\mathbf{1 k}$ afforded a mixture of products: 2-phenylacetaldehyde $\mathbf{2 k}$ isolated in low yields (10\%), benzaldehyde $2 \mathbf{b}$ as the main product (40\%) derived from an oxidative C-C cleavage of $2 \mathbf{k}$, $^{33}$ and traces of benzoic acid as over-oxidation of benzaldehyde. 2-Phenylpropylamine $1 \mathbf{j}$ yielded acetophenone $\mathbf{6}$ as the only product. Compound 6 probably derived from an initial oxidation of $\mathbf{1 j}$ to 2-phenylpropanal which underwent an oxidative C-C cleavage to 6 as previously observed for phenylpropionic aldehydes. ${ }^{34}$ Tryptamine 11 provided only polymerized products, and we could not obtain a successful oxidation for any tested cyclic or linear aliphatic amine (Table 3, entries 13-16) thus revealing a strong selectivity towards the oxidation of benzylic moiety.

We then evaluated a series of $\mathrm{N}$-benzyl secondary amines 712, which were prepared via reduction of the corresponding 


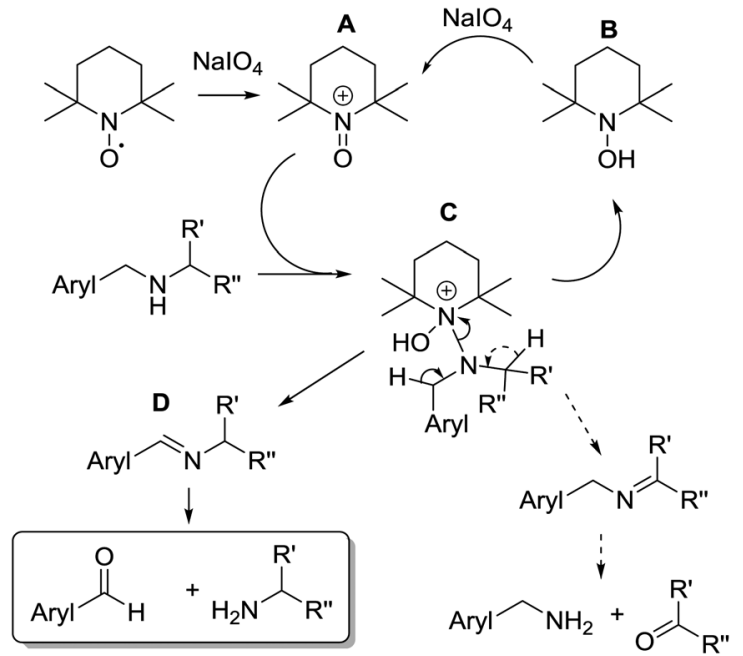

Scheme 1 Proposed mechanism for selectivity in secondary amine oxidation with $\mathrm{NaIO}_{4} / \mathrm{TEMPO}$.

imines or via a one-step reductive amination starting from the corresponding aldehydes and amines (see ESI $\dagger$ ) (Table 4).

Oxidation of symmetrical bis-p-methoxy-benzylamine 7 exclusively gave the aldehyde $2 \mathrm{a}$ in good yields with 2.2 equiv. of periodate (Table 4 , entry 2). In the presence of 1.1 equiv. of TEMPO (Table 4 , entry 1 ) only traces of amine 1a, intermediate of the first oxidation step, were obtained. This could be due to a slower reactivity of the secondary amine 7 than the primary amine intermediate 1a, similarly to the oxidation with TEMPO of secondary alcohols compared to the primary ones. ${ }^{35}$
Unsymmetrical amines 8-12 were selectively oxidized only on the benzyl moiety, consequently yielding pOMe-benzaldehyde 2a and the aliphatic amine that were easily separated via liquid-liquid acid-base extraction (see Experimental section) as pure products in satisfactory to excellent yields. As a general observation, the yield of aldehyde $\mathbf{2 a}$ was in all cases increased by doubling the equivalents of sodium periodate (Table 4, entries 1-8). The developed protocol could be then used to obtain selective deprotection of benzylic groups on secondary amines.

A tentative analysis of TEMPO-mediated oxidation pathway could account for the observed selectivity. TEMPO is a stable nitroxide radical which undergoes a one-electron oxidation to the active oxidizing agent, the oxammonium cation A (Scheme 1). The oxidation process provides the reduced form as the neutral hydroxylamine B. Nitroxide radicals can be used in a catalytic amount in the presence of a terminal oxidant and it has been already demonstrated the ability of sodium periodate to behave as terminal oxidant in alcohol oxidations with TEMPO as catalyst. ${ }^{36}$ Considering the mechanism proposed for alcohol oxidation by oxammonium cation, ${ }^{37}$ a tentative mechanism for the selective oxidation of secondary amines in aqueous medium could be formulated.

The reaction is initiated by the attack of the amine on $\mathbf{A}$ leading to the complex $\mathbf{C}$, beta-hydrogen elimination then produces two possible imines as intermediates and the hydroxylamine $\mathbf{B}$ which is re-oxidized to oxammonium $\mathbf{A}$ by periodate. The $\mathrm{H}$ elimination selectively addressed the benzylic hydrogen rather than the aliphatic one probably on account of a lower $\mathrm{C}-\mathrm{H}$ bond dissociation energy of the benzylic

Table 5 Oxidation of cyclic amines with $\mathrm{NaIO}_{4} / \mathrm{TEMPO}(10 \mathrm{~mol} \%)^{a}$

En.

${ }^{a}$ Reaction conditions: see GP4 in the Experimental section. ${ }^{b}$ Isolated yields by solvent extraction after acid and basic work-up (see Experimental section); the yield ratios of products $15: 16: 17$ were determined via ${ }^{1} \mathrm{H}$ NMR analysis. 
position. ${ }^{37,38}$ In the aqueous medium the aryl-conjugated imine D undergoes hydrolysis to give the target aryl-aldehyde and amine.

Finally, three aromatic bicyclic amines 1q-s were evaluated. Amine 1q underwent oxidative aromatization and quantitatively gave indole, as well as 1r provided quinoline 14 in $74 \%$ isolated yield with 2 equiv. of sodium periodate and 1 equiv. of acetic acid.

1,2,3,4-Tetrahydroisoquinoline 1 s with 1 equiv. of periodate gave the imine $\mathbf{1 5}$ as the main product (78\% yield) and small amounts of the amide $\mathbf{1 6}$ (Table 5 entry 4), but on enhancing the equivalents of periodate increased amounts of the amide $\mathbf{1 6}$ and the formation of the isoquinoline 17 were detected (Table 5 entries 5 and 6). ${ }^{1} \mathrm{H}$ NMR spectra representing products distribution in crude mixture of entry 6 is reported in Fig. $3 \mathrm{~S}$ in ESI. $\dagger$ Amide 16 could derive from an initial $\mathrm{H}_{2} \mathrm{O}$ addition to imine $\mathbf{1 5}$ and further oxidation of the intermediate aminol to amide, as recently reported in $\alpha$-oxygenation of amines to amides catalyzed by gold nanoparticles in $\mathrm{H}_{2} \mathrm{O}{ }^{39}$

\section{Conclusions}

Selectivity and sustainable reaction conditions are key issues for the development of new eco-friendly methodologies for amine oxidation. Indeed, selectivity is often a critical point because of the large number of possible products and many systems for amine oxidation still need metal-containing reagents and produce toxic or hazardous wastes. According to this, we investigated some inorganic metal-free oxidants for oxidation of amines. $\mathrm{NaIO}_{4} /$ TEMPO turned out to be the most efficient and selective system for benzylamines oxidation to benzaldehydes in aqueous-organic medium. If combined with 1 equiv. of acetic acid, this system provided complete conversions of substituted benzylamines to the corresponding benzaldehydes that were efficiently isolated in good to excellent yields. Oxidation of secondary amines gave selective oxidation on the benzylic portion thus realizing an oxidative deprotection of the $N$-benzyl group with an easy amine recovery. A mechanism considering the selectivity for secondary amines oxidation was formulated. Finally, application of the optimized oxidative method to some cyclic amines such as dihydroindole, tetrahydroquinoline and tetrahydroisoquinoline confirmed its efficiency mainly providing the corresponding aromatic derivatives.

\section{Experimental}

\section{General methods}

Commercial reagents (reagent grade, >99\%) were used as received without additional purification. Anhydrous solvents $\left(\mathrm{CH}_{2} \mathrm{Cl}_{2}, \mathrm{MeOH}, \mathrm{CH}_{3} \mathrm{CN}\right)$ were obtained commercially. ${ }^{1} \mathrm{H}$ and ${ }^{13} \mathrm{C}$ NMR spectra were recorded with an INOVA 400 instrument with a $5 \mathrm{~mm}$ probe. All chemical shifts are quoted relative to deuterated solvent signals ( $\delta$ in ppm and $J$ in $\mathrm{Hz}$ ). The purities of the target compounds were assessed as being $>95 \%$ by HPLCMS analysis. FTIR spectra: Brucker Alpha instrument, measured as films between $\mathrm{NaCl}$ plates; wave numbers are reported in $\mathrm{cm}^{-1}$. HPLC-MS: Agilent Technologies HP1100 instrument, equipped with a ZOBRAX-Eclipse XDB-C8 Agilent Technologies column; mobile phase: $\mathrm{H}_{2} \mathrm{O} / \mathrm{CH}_{3} \mathrm{CN}, \quad 0.4$ $\mathrm{mL} \mathrm{min}{ }^{-1}$, gradient from 30 to $80 \%$ of $\mathrm{CH}_{3} \mathrm{CN}$ in $8 \mathrm{~min}, 80 \%$ of $\mathrm{CH}_{3} \mathrm{CN}$ until $25 \mathrm{~min}$, coupled with an Agilent Technologies MSD1100 single-quadrupole mass spectrometer, full scan mode from $m / z=50$ to 2600, in positive ion mode. GC-MS: HewlettPackard 5971 spectrometer with GC injection and EI ionization at $70 \mathrm{eV}$ coupled with an Agilent Technologies MSD1100 single-quadrupole mass spectrometer, reported as: $\mathrm{m} / \mathrm{z}$ (rel. intensity).

Starting amines 1a-1t are commercially available; synthetized imines 4a, 4n, 4o, 4t and secondary amines 7-11 are known. The obtained oxidation products: aldehydes $\mathbf{2 a - 2 k}$, acids 3a-3b, nitrile 5a, compounds 6, 13-17 are known. Structures and purities of all the obtained known compounds were assessed by ${ }^{1} \mathrm{H}$ NMR and HPLC-MS analysis or by ${ }^{1} \mathrm{H}$ NMR and GC-MS analysis for compounds 13-17 and were fully consistent with data reported in databases. Imines $4 \mathbf{4 a}, \mathbf{4 m}, \mathbf{4 n}, \mathbf{4 o}, \mathbf{4 t}$ and secondary amines 7-12 synthesis are reported in ESI. $\dagger^{1} \mathrm{H}$ NMR and ${ }^{13} \mathrm{C}$ NMR of new compounds $\mathbf{4 m}$ and $\mathbf{1 2}$ is reported in ESI $\dagger$ together with ${ }^{1} \mathrm{H}$ NMR representative crude reaction mixtures (Fig. 1S and $2 \mathrm{~S}^{\dagger}$ ).

General procedure for $\boldsymbol{p}$-methoxybenzylamine oxidation (GP1). In a $25 \mathrm{~mL}$ two-necked flask, $p$-methoxybenzylamine 1a ( $0.4 \mathrm{mmol}, 1$ equiv.) was dissolved in the corresponding solvent or solvent mixture (see Tables 1 and 2). $\mathrm{AcOH}$ (if specified), TEMPO (if specified) and the oxidant were then added according to what reported in Tables 1 and 2. The mixture was then quenched (reaction time specified in Tables 1 and 2) with $\mathrm{HCl}$ $1 \mathrm{M}$ and extracted with EtOAc $(3 \times 10 \mathrm{~mL})$. The collected organic layers were dried on anhydrous $\mathrm{Na}_{2} \mathrm{SO}_{4}$, filtered and concentrated to isolate $p$-anisaldehyde $\mathbf{2 a}$ (or compounds $\mathbf{3 a}, \mathbf{4 a}$, and $\mathbf{5 a}$ if specified). The aqueous phase was then basified with $\mathrm{NaOH}$ $1 \mathrm{M}$ and extracted with EtOAc $(3 \times 10 \mathrm{~mL})$. The organic layers were dried on anhydrous $\mathrm{Na}_{2} \mathrm{SO}_{4}$, filtered and concentrated to isolate the starting amine 1a, if present. The amount of the residual 1a allowed the determination of conversion\%.

General procedure for amines oxidation to aldehydes with sodium periodate (GP2). In a $25 \mathrm{~mL}$ two-necked flask, $\mathrm{AcOH}$ (0.4 mmol, 1 equiv.), TEMPO ( $0.04 \mathrm{mmol}, 0.1$ equiv.) and $\mathrm{NaIO}_{4}$ ( $0.4 \mathrm{mmol}, 1$ equiv.) were added to a solution of the desired amine 1a-1p (0.4 mmol, 1 equiv.) in a $2: 1$ ratio of $\mathrm{H}_{2} \mathrm{O} / \mathrm{CH}_{3} \mathrm{CN}$ $(15 \mathrm{~mL})$ (see Table 3$)$. After $20 \mathrm{~h}$ the mixture was quenched with $\mathrm{HCl} 1 \mathrm{M}$ and extracted with EtOAc or $\mathrm{Et}_{2} \mathrm{O}(3 \times 10 \mathrm{~mL})$. The collected organic layers were dried on anhydrous $\mathrm{Na}_{2} \mathrm{SO}_{4}$, filtered and concentrated to isolate the corresponding aldehydes $\mathbf{2 a - k}$ or compounds $\mathbf{6}$ and $\mathbf{3 b}$ where specified. The aqueous phase was then basified with $\mathrm{NaOH} 1 \mathrm{M}$ and extracted with EtOAc or $\mathrm{Et}_{2} \mathrm{O}(3 \times 10 \mathrm{~mL})$. The organic layers were dried on anhydrous $\mathrm{Na}_{2} \mathrm{SO}_{4}$, filtered and concentrated to isolate the residual starting amines $\mathbf{1 a - 1 1}$, if present. The residual aliphatic amines 1m-1p were isolated as ammonium salts in the basic organic extract by adding one equivalent of trifluoroacetic acid (TFA) just before the final solvent evaporation.

General procedure for secondary amines oxidation with sodium periodate (GP3). In a $25 \mathrm{~mL}$ two-necked flask, $\mathrm{AcOH}$ 
( 0.4 mmol, 1 equiv.), TEMPO ( 0.04 mmol, 0.1 equiv.) and $\mathrm{NaIO}_{4}$ (as specified in Table 4) were added to a solution of the desired secondary amine 7-12 (0.4 mmol, 1 equiv.) in a $2: 1$ ratio of $\mathrm{H}_{2} \mathrm{O} / \mathrm{CH}_{3} \mathrm{CN}(10 \mathrm{~mL}$ ) (see Table 4$)$. After $20 \mathrm{~h}$ the mixture was quenched with $\mathrm{HCl} 1 \mathrm{M}$ and extracted with EtOAc or $\mathrm{Et}_{2} \mathrm{O}(3 \times$ $10 \mathrm{~mL}$ ). The collected organic layers were dried on anhydrous $\mathrm{Na}_{2} \mathrm{SO}_{4}$, filtered and concentrated to isolate $p$-anisaldehyde $2 \mathbf{a}$. The aqueous phase was then basified with $\mathrm{NaOH} 1 \mathrm{M}$ and extracted with EtOAc or $\mathrm{Et}_{2} \mathrm{O}(3 \times 10 \mathrm{~mL})$. The organic layers were dried on anhydrous $\mathrm{Na}_{2} \mathrm{SO}_{4}$, filtered and concentrated to isolate amines $\mathrm{RNH}_{2}$ (1a, $\mathbf{1 j}, \mathbf{1 m}, \mathbf{1 n}, \mathbf{1 o}$, and $\mathbf{1 t}$, see Table 4). When specified, amines were isolated as ammonium salts in the basic organic extract by adding one equivalent of trifluoroacetic acid (TFA) just before the final solvent evaporation.

General procedure for cyclic amines oxidation with sodium periodate (GP4). In a $25 \mathrm{~mL}$ two-necked flask, AcOH $(0.4 \mathrm{mmol}$, 1 equiv., if specified in Table 5), TEMPO ( 0.04 mmol, 0.1 equiv.) and $\mathrm{NaIO}_{4}(0.4 \mathrm{mmol}$, as specified in Table 5$)$ were added to a solution of the desired amine 1q-1s ( $0.4 \mathrm{mmol}, 1$ equiv.) in a $2: 1$ ratio of $\mathrm{H}_{2} \mathrm{O} / \mathrm{CH}_{3} \mathrm{CN}(10 \mathrm{~mL})$. After $20 \mathrm{~h}$ the mixture was quenched with $\mathrm{HCl} 1 \mathrm{M}$ and extracted with EtOAc or $\mathrm{Et}_{2} \mathrm{O}(3 \times$ $10 \mathrm{~mL}$ ). The collected organic layers were dried on anhydrous $\mathrm{Na}_{2} \mathrm{SO}_{4}$, filtered and concentrated to isolate the oxidation products 13, 15 (in its protonated form) or 16 (see Table 5). The aqueous phase was then basified with $\mathrm{NaOH} 1 \mathrm{M}$ and extracted with EtOAc or $\mathrm{Et}_{2} \mathrm{O}(3 \times 10 \mathrm{~mL})$. The organic layers were dried on anhydrous $\mathrm{Na}_{2} \mathrm{SO}_{4}$, filtered and concentrated to isolate the starting amines 1q-1s if present, and the oxidation products 14, 15 and 17 (see Table 5).

\section{Conflicts of interest}

There are no conflicts to declare.

\section{Acknowledgements}

This work was supported by University of Bologna research funding RFO 2016.

\section{Notes and references}

1 (a) J. H. Teles, I. Hermans, G. Franz and R. A. Sheldon, Oxidation, in Ullmann's Encyclopedia of Industrial Chemistry, Wiley-VCH Verlag GmbH \& Co. KGaA, Weinheim, 2015, DOI: 10.1002/14356007.a18_261.pub; (b)

F. Cavani and J. H. Teles, ChemSusChem, 2009, 2, 508-534.

2 S. S. Rawalay and H. Shechter, J. Org. Chem., 1967, 32, 31293131.

3 R. G. R. Bacon and W. J. W. Hanna, J. Chem. Soc., 1965, 49624968.

4 S. Sobhani and M. F. Maleki, Synlett, 2010, 383-386.

5 S. Sobhani, S. Aryanejad and M. F. Maleki, Helv. Chim. Acta, 2012, 95, 613-617.

6 S. Chandrasekhar, G. P. K. Reddy, C. Nagesh and C. R. Reddy, Tetrahedron Lett., 2007, 48, 1269-1271.
7 (a) J. Srogl and S. Voltrova, Org. Lett., 2009, 11, 843-845; (b) S. Naya, T. Niwa, R. Negishi, H. Kobayashi and H. Tada, Angew. Chem., Int. Ed., 2014, 53, 13894-13897.

8 N. Iqbal and E. J. Cho, Adv. Synth. Catal., 2015, 357, 21872192.

9 (a) R. Tang, S. E. Diamond, N. Neary and F. Mares, J. Chem. Soc., Chem. Commun., 1978, 13, 562; (b) A. J. Bailey and B. R. James, Chem. Commun., 1996, 20, 2343-2344; (c) K. Yamaguchi and N. Mizuno, Angew. Chem., Int. Ed., 2003, 42, 1480-1483; (d) L. Aschwanden, T. Mallat, F. Krumeich and A. Baiker, J. Mol. Catal. A: Chem., 2009, 309, 57-62; (e) M. H. So, Y. Liu, C. M. Ho and C. M. Che, Chem.-Asian J., 2009, 4, 1551-1561; (f) M. Largeron, Eur. J. Org. Chem., 2013, 5225-5235; (g) H. Yu, Y. Zhai, G. Dai, S. Ru, S. Han and Y. Wei, Chem.-Eur. J., 2017, 23, 13883-13887.

10 F. Su, S. C. Mathew, L. Mohlmann, M. Antonietti, X. Wang and S. Blechert, Angew. Chem., Int. Ed., 2011, 50, 657-660.

11 W. Zhao, C. Liu, L. Cao, X. Yin, H. Xu and B. Zhang, RSC Adv., 2013, 3, 22944-22948.

12 S. Sarina, H. Zhu, E. Jaatinen, Q. Xiao, H. Liu, J. Jia, C. Chen and J. Zhao, J. Am. Chem. Soc., 2013, 13, 5793-5801.

13 Z. J. Wang, S. Ghasimi, K. Landfesterand and K. A. I. Zhang, Adv. Mater., 2015, 27, 6265-6270.

14 J. H. Ko, N. Kang, N. Park, H.-W. Shin, S. Kang, S. M. Lee, H. J. Kim, T. K. Ahn and S. U. Son, ACS Macro Lett., 2015, 4, 669-672.

15 S. Naya, K. Kimura and H. Tada, ACS Catal., 2013, 3, 10-13. 16 S. Naya, T. Niwa, R. Negishi, H. Kobayashi and H. Tada, Angew. Chem., 2014, 126, 14114-14117.

17 H. Chen, C. Liu, M. Wang, C. Zhang, N. Luo, Y. Wang, H. Abroshan, G. Li and F. Wang, ACS Catal., 2017, 7, 36323638.

18 D. Lenoir, Angew. Chem., Int. Ed., 2006, 45, 3206-3210.

19 M. Largeron, Org. Biomol. Chem., 2017, 15, 4722-4730.

20 P. Galletti, M. Pori, F. Funiciello, R. Soldati, A. Ballardini and D. Giacomini, ChemSusChem, 2014, 7, 2684-2689.

21 P. Galletti, F. Funiciello, R. Soldati and D. Giacomini, Adv. Synth. Catal., 2015, 357, 1840-1848.

22 (a) R. Ciriminna and M. Pagliaro, Org. Process Res. Dev., 2010, 14, 245-251 and references cited therein; $(b)$ R. A. Sheldon and I. W. C. E. Arends, Adv. Synth. Catal., 2004, 346, 10511071.

23 A. L. Bartelson, K. M. Lambert, J. M. Bobbitt and W. F. Bailey, ChemCatChem, 2016, 8, 3421-3430.

24 M. L. Contente, F. Dall'Oglio, L. Tamborini, F. Molinari and F. Paradisi, ChemCatChem, 2017, 9, 3843-3848.

25 D. Zheng, X. Zhou, B. Cui, W. Han, N. Wan and Y. Chen, ChemCatChem, 2017, 9, 937-940.

26 S. Gaspa, A. Porcheddu, A. Valentoni, S. Garroni, S. Enzo and L. De Luca, Eur. J. Org. Chem., 2017, 5519-5526.

27 R. Brisar, D. Hollmann and E. Mejia, Eur. J. Org. Chem., 2017, 5391-5398.

28 A. Bana, H. Valizadeh, A. Heydari and A. Moghlml, Synlett, 2017, 28, 2315-2319.

29 G. F. P. de Souza, T. W. von Zuben and A. G. Salles Jr., ACS Sustainable Chem. Eng., 2017, 5, 8439-8446.

30 T. J. Collins, Acc. Chem. Res., 2002, 35, 782-790. 
31 (a) A. Sudalai, A. Khenkin and R. Neumann, Org. Biomol. Chem., 2015, 13, 4374-4394; (b) A. Lauterbach, G. Ober, Iodine and iodine compounds, in Kirk Othmer Encyclopedia of Chemical Technology, John Wiley \& Sons, Hoboken, NJ, 5th edn, 2005, vol. 14, pp. 353-380, DOI: 10.1002/ 0471238961.0915040912012120.a01.pub2.

32 P. L. Anelli, C. Biffi, F. Montanari and S. Quici, J. Org. Chem., 1987, 52, 2559-2562.

33 (a) Q. Xing, H. Lv, C. Xia and F. Li, Chem. Commun., 2016, 52, 489-492; (b) S.-J. Jin, P. K. Arora and L. M. Sayre, J. Org. Chem., 1990, 55, 3011-3018.

34 P. Galletti, M. Pori and D. Giacomini, Synlett, 2010, 17, 26442648.
35 M. F. Semmelhack, C. S. Chou and D. A. Cortes, J. Am. Chem. Soc., 1983, 105, 4492-4494.

36 M. Lei, R.-J. Hu and Y.-G. Wang, Tetrahedron, 2006, 62, 89288932.

37 (a) W. F. Bailey, J. M. Bobbitt and K. B. Wiberg, J. Org. Chem., 2007, 72, 4504-4509; (b) F. d'Acunzo, P. Baiocco, M. Fabbrini, C. Galli and P. Gentili, Eur. J. Org. Chem., 2002, 4195-4201.

38 Y.-R. Luo and J.-P. Cheng, Bond Dissociation Energies in Polyatomic Molecules in Handbook of Chemistry and Physics, CRC press, 98th edn, 2017-2018.

39 X. Jin, K. Kataoka, T. Yatabe, K. Yamaguchi and N. Mizuno, Angew. Chem., Int. Ed., 2016, 55, 7212-7217. 